\title{
Practical implementation of an improved standby boost uninterruptible power supply
}

\author{
Candidus U. Eya
}

Electrical Engineering University of Nigeria, Nsukka Enugu State Nigeria

\section{Email address:}

ecandidus@yahoo.com

\section{To cite this article:}

Candidus U. Eya. Practical Implementation of an Improved Standby Boost Uninterruptible Power Supply. International Journal of Energy and Power Engineering. Special Issue: Energy Conversion and Management. Vol. 3, No. 6-3, 2014, pp. 1-7. doi: $10.11648 /$ j.ijepe.s.2014030603.11

\begin{abstract}
This paper proposes a single phase pulse-width modulated (PMW) voltage source uninterruptible power supply known as an improved standby boost uninterruptible power supply (ISBUPS) which centers on keeping the output voltage of the inverter system of the UPS at constant voltage of $220 \mathrm{~V}$ AC and ripple free when utility power supply fails. This concept is achieved by incorporating proportional integral (PI) controller, boost converter and L-C filter at inverter control section. In this research, apart from stabilizing the inverter output voltage of inverter at 220VAC in standby mode, 0.96 modulation index is also realized. The total harmonic distortion of the system is reduced down to $5.05 \%$. This proposed system has its applications at homes, offices and in business centers especially in Nigeria where electrical power instability is high now.
\end{abstract}

Keywords: Uninterruptible Power Supply, PWM, Inverter, Modulation Index, PI Controller

\section{Introduction}

Globally, electricity has a vital role with its capability to merge electrical power and intelligence together to make life easy for human beings. Nearly all the systems that perform vital roles in our daily activities need electrical energy to operate. Electricity increases production, efficiency, safety, reliability, and comfort of living. Interruptions in electric power line cannot be permitted in those sensitive areas involving safety, continuous industrial processes, security and data protection in information technologies [1-2].

Though previously backup generators were satisfactory to get power in case of interruption in the utility, yet, long delay in switching and starting of generators as seen today is not sufficient to meet up with the immediate demands of electrical power in those areas [1-2]. Such delays grossly affect critical loads such as computers, internet providers, telecom service providers, etc. Even though the electric utility industry has made remarkable efforts for uninterrupted power line and undistorted line voltage, unavoidably still there exist problems such as voltage fluctuations and spikes [2]. In order to avoid such problems, Uninterruptible power supply (UPS) systems with continuous and clean output power are utilized [1-3]. Uninterruptible Power Supply (UPS) System could be defined as electrical device that provides emergency power to the power loads when the input power source, like mains power, fails or abrupt blackout [1]. Basically it is made up of rectifier, charger, battery, filters, inverter, protective devices and accessories that automatically provide continuous electric power supply [1-2]. A UPS varies from an auxiliary or standby generator because it provides near-immediate protection from input power interruptions, by supplying energy stored in batteries [2-3]. The on-battery runtime of most UPS sources is relatively short down (only a few minutes) but sufficient to start a standby power source or properly shut down the protected equipment [2-5].

A conventional standby power supply system is provided for supplying normal AC power to critical load AC power during the normal operating conditions, and for supplying emergency AC power to the loads during the failure of AC power source [3-5]; however voltage stabilization of inverter output at 220VAC was not assured. Then, since the conventional voltage source inverter (VSI) used in conventional standby UPS system and other applications such as photovoltaic systems (PV), AC motor drives has relatively small input voltage [6-7], it is needed to be stepped up in order to increment the output voltage amplitude to meet up with the non-linear load requirements and other electrical challenges. 
[8-12] utilized parallel active power filters (APFs) to reduce the distortion effects on their systems caused by non-linear loads. One of their problems is that they have complex control systems. In addition to that, the total harmonic contents are high due to high switching power losses. The line-interactive UPS system done by [13]; used unified power quality conditioners in achieving the series and parallel filtering active capability. It was done by combination of two single-phase full bridge converters coupled to DC links; though performed creditably, yet it is bulky and consumes a lot of spaces. In addition to that, its percentage of total harmonic distortion is high $(48 \%)$. So in order to overcome the above short-comings in standby UPS family and other related inverter based applications, the improved standby boost uninterruptible power supply (ISBUPS) is proposed in this work. This proposed improved standby boost uninterruptible power supply (ISBUPS) aims at: providing a rapid and appreciable non-diminutive replacement of power outage to sensitive appliances, offering protection to the power loads from voltage fluctuations and spikes, ensuring no record of data losses in those appliances it is protecting, mitigation of total harmonic contents of the inverter output down to $5.05 \%$, and mostly maintaining constant output voltage stabilization at $220 \mathrm{AC}, 50 \mathrm{~Hz}$ with the aid of PI controller and boost converter; once utility power is disturbed. It is different from the ordinary stand-by UPS because its inverter section has a simple feed-back control system that ensures proper voltage stabilization of the dc/ac converter output, once the power utility is cut off. But both standby uninterruptible power systems operate in the same principle. The principle is that once there is power from the mains, their inverters will automatically go into redundancy unlike in other types of UPS and vice versa

\section{Block Diagram of an Improved Standby Boost Uninterruptible Power Supply}

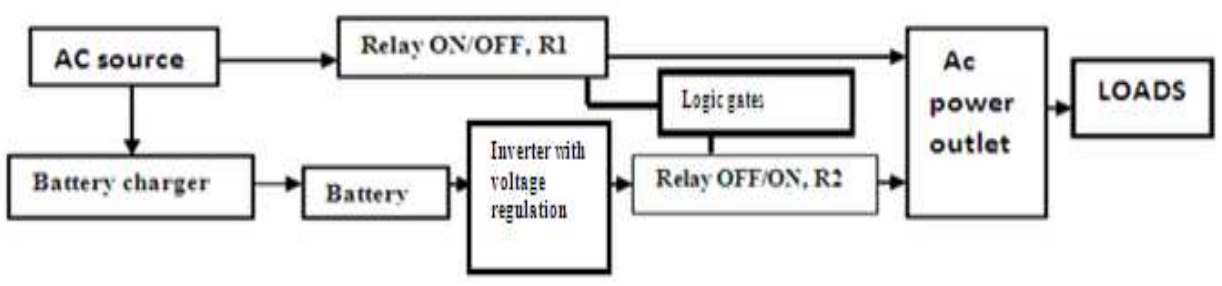

Figure 1a. Block diagram of the proposed improved standby boost uninterruptible power supply (ISBUPS)

The block diagram in figure 1.a shows that under normal running of ac power, the upper relay, R1will turn ON while the lower relay, R2 connecting the inverter output will turn OFF. This delivers the ac power to the ac load through the power outlet and protective devices. Besides, it also charges the battery through the battery charger. This charger rectifies the ac power to dc power for normal sustaining the live of the battery [4-6]. This means that the two relays are automatically controlled using logic gates. When there is abrupt power failure or voltage surge, the Relay, R1 automatically turns OFF and this will trigger the relay R2 to turn ON. During the off -period of utility power, the PI controller communicates the boost converter about the level of inverter output so that it will adjust the duty cycle for compensating the voltage levels. Due to the capacity of the battery, this ISBUPS stays back between the ranges of 45 -58 minutes to enable the system under its control to short down properly.

\section{The Analytical Design of Proportional - Plus - Integral (PI) Controller}

It is a controller that calculates an error voltage or current between a measured processed variable and a desired reference value (set point) [1]. The PI Controller algorithm involves two parameters: proportional and integral values.
The integral term speeds up the action based on the rate of sum of the error compensation by adjusting the band-width of the signals while the action that will be taken based on the information got by either sending the signal to turn $\mathrm{ON}$ or OFF is carried out by proportional term. The PI controller stabilizes voltage or current at a desired level.

The transfer function of PI controller is given by

$$
G_{C}(s)=K_{p}+\frac{K_{1}}{s}
$$

Where $\mathrm{K}_{\mathrm{p}}$ - gain of the proportional term, $\frac{K_{1}}{S}$ transfer function of the integral term, I-integral term, pproportional term

With standard design technique, steady-state accuracy is achieved by the proportional term, while the integral term allows the needed bandwidth to be adjusted.

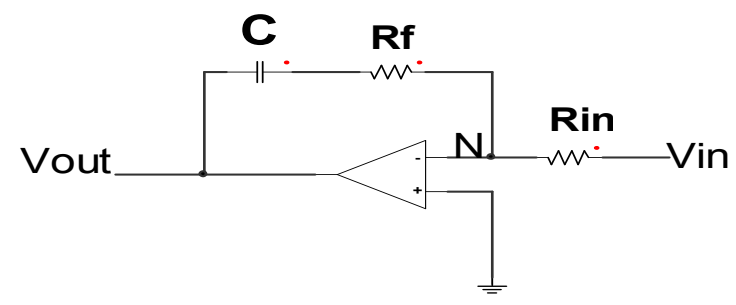

Figure 1b. Circuit symbol for PI controller 
A simplified circuit of the PI controller is shown in figure 1b. Considering the sum of current at node, $\mathrm{N}$, of the inverting terminal of the operation amplifier is equal to zero

$$
\begin{gathered}
\frac{V_{\text {in }}-V_{N}}{R_{\text {in }}}=\frac{V_{N}-V_{\text {out }}}{R_{f}+\frac{1}{s C}} \\
\left(V_{\text {in }}-V_{N}\right)\left(R_{f}+\frac{1}{s C}\right)=R_{\text {in }}\left(V_{N}-V_{\text {out }}\right)
\end{gathered}
$$

Making $V_{N}$ the subject formula

$$
V_{N}=\frac{V_{\text {in }} R_{f}+\frac{V_{\text {in }}}{s C}+R_{\text {in }} V_{\text {out }}}{R_{\text {in }}+\frac{1}{s C}+R_{2}}
$$

Considering the voltage at positive terminal (non-inverting part),

$$
\mathrm{Vp}=0
$$

Equating equation 4 and 5

$$
\frac{V_{\text {out }}}{V_{\text {in }}}=-\left[\frac{R_{f}+\frac{1}{s C}}{R_{\text {in }}}\right]
$$

Taking the absolute expression of equation 7

$$
\left|\frac{V_{\text {out }}}{V_{\text {in }}}\right|=\frac{R_{f}}{R_{\text {in }}}+\frac{1}{s C R_{\text {in }}}
$$

Comparing equation 1 and 7 yields

$$
\left.\begin{array}{rl}
G_{C}(s) & =\left|-\frac{V_{\text {out }}}{V_{\text {in }}}\right|=\frac{V_{\text {out }}}{V_{\text {in }}} \\
K_{p} & =\frac{R_{f}}{R_{\text {in }}} \\
K_{1} & =\frac{1}{C R_{\text {in }}}
\end{array}\right\}
$$

$G_{C}(s)$-PI controller gain, s-Laplace operator, $C$ capacitance, $K_{p}$-gain of the proportional term, $R_{f}$ feed-back resistance, $R_{\text {in }}$-input resistance, $V_{\text {out }}$-output resistance $\mathrm{V}_{\mathrm{N}}$ - -Voltage at inverting terminal.

Table 1. Components for designing PI Controller

\begin{tabular}{cc}
\hline Material & Values \\
\hline Capacitance of capacitor, $\mathrm{C}$ & $470 \mathrm{uF}, 63 \mathrm{~V}$ \\
Input Resistance, $\mathrm{R}_{\mathrm{in}}$ & $50 \Omega$ \\
Feed-back Resistance, $\mathrm{R}_{\mathrm{f}}$ & $60 \Omega$ \\
Input voltage & $12 \mathrm{VDC}$ \\
\hline
\end{tabular}

The table. 1 shows the component values for designing the PI controller and all those components were sourced locally.

\section{Designing of the Triggering Signals of the Inverter Switches}

\subsection{Generation of Biasing Regulated Voltage}

This could be done by either rectifying the ac power or directly using direct current/voltage source to get regulated dc voltage meant for proper biasing of other components. The rectification in this work was done by connecting the full bridge rectifier, IN4007 to the center tapped transformer. This produced a full wave rectified signals. The capacitors are used to produce a pure 12VDC. The circuit for this generation is shown in figure 2 . The table 2 shows the circuit component values. Then from the biased circuit components, the regulated sine wave signals at $50 \mathrm{~Hz}$ and a triangular wave signals at about $20 \mathrm{kHz}$ are generated and compared at comparators to get pulse-width modulated signals. These pulses are further processed and then used for firing the power switches. The following figures 2 and 3 analyzed the processes clearly. The table. 3 illustrates the values of components for generating firing signals.

Table 2. Components for generation of biasing DC voltage

\begin{tabular}{cc}
\hline Material & Values \\
\hline Center tapped Transformer & $220 \mathrm{VAC} / 50 \mathrm{~Hz}$ \\
Full bridge rectifier & $\mathrm{IN} 4007 / 600-1000 \mathrm{~V}$ \\
Capacitors & $2 \mathrm{X} 2200 \mathrm{uF}, 2 \mathrm{X} 470 \mathrm{uF}$ \\
Positive Regulator & $78 \mathrm{~L} 12$ \\
Negative Regulator & $79 \mathrm{~L} 12$ \\
\hline
\end{tabular}

Table 3. Components for generation of firing signals

\begin{tabular}{cc}
\hline Material & Values \\
\hline Variable resistors & $50 \mathrm{k} \Omega, 20 \mathrm{k} \Omega, 30 \mathrm{k} \Omega$, \\
Jumper wires & $1 \mathrm{roll}$ \\
Capacitors & $2 \mathrm{x} 2200 \mathrm{uF}, 2 \times 470 \mathrm{uF}$ \\
Comparators & $2 \times 0.10 \mathrm{uF}, 2 \times 0.01 \mathrm{uF}$ \\
Zener diode & $\mathrm{TL} 084,12 \mathrm{~V}, 1.00 \mathrm{~A}$ \\
Logic gates & - \\
Isolators & $\mathrm{HEX} 4049 \mathrm{~B}, 4071 \mathrm{~B}$ \\
Fixed resistors & $4 \mathrm{~N} 35$ \\
Led(red and yellow colors) & $1 \mathrm{k} \Omega, 10 \mathrm{k} \Omega$ \\
\hline
\end{tabular}

The figures $2 \mathrm{a}$ and $2 \mathrm{~b}$ are the circuits that were drawn and simulated in livewire software for getting the 12VDC. So for the realistic implementation, bread board, a center tapped transformer of $220 \mathrm{ac} 50 \mathrm{~Hz}$ input and $12 \mathrm{~V}-0-12 \mathrm{~V}$ output, the full bridge rectifier, two $3300 \mathrm{uF}, 63 \mathrm{~V}$ capacitors, voltage regulators $78 \mathrm{~L} 12 \mathrm{~V}$ for positive voltage and $79 \mathrm{~L} 12 \mathrm{~V}$ for negative voltage were used. The figure $2 \mathbf{c}$ showed the practical circuit and figure $2 \mathrm{~d}$ is the oscilloscope display of the output from regulators 78L12 and 79L12. Then in order to obtain the pure dc voltages, two $470 \mathrm{uF}, 63 \mathrm{~V}$ were equally applied for smooth filtering of current ripples. After this, the next level is for producing the carrier wave and the sine wave signals, these two signals are produced by sequential 
connection of variable resistors of 20-kohms, 50-kohms,30-kohms, $0.10 \mathrm{uF}, 0.01 \mathrm{uF}$ capacitors , jumper wires and zener diodes as shown in figure $3 \mathrm{a}$. When the carrier wave and the sine wave signals passed through comparator of TLO84, the pulse-width modulated signals is

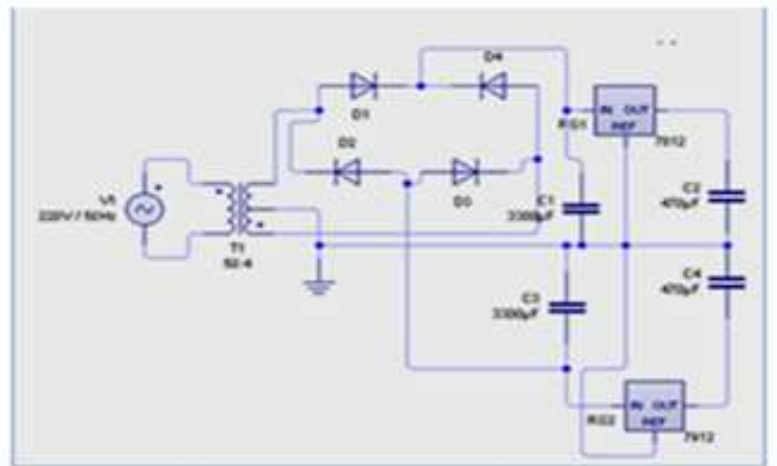

(2a)

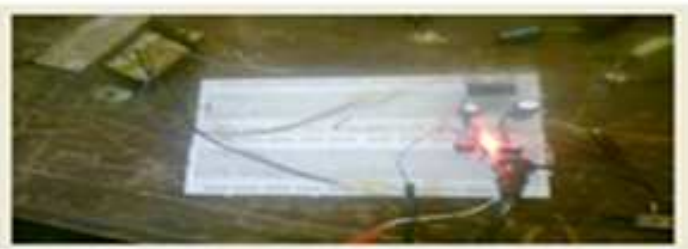

$(2 c)$ engendered. Then the sine wave signal was then phase-shifted at angle $180^{\circ}$ and equally compared to produce opposite pulses. The real circuit and their respective signals are shown below in figure 3 .

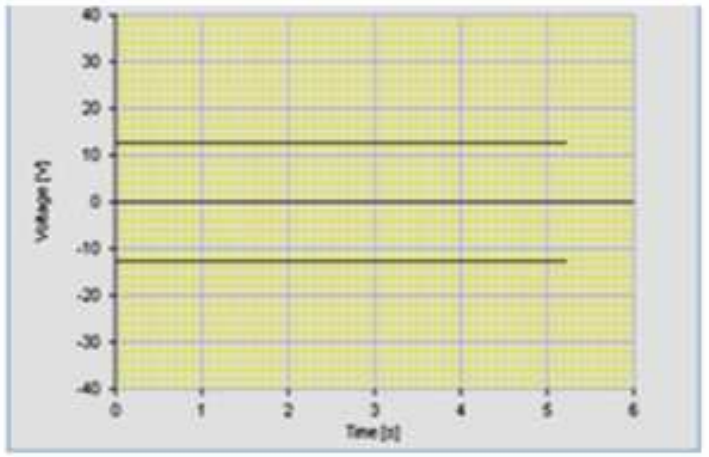

(2b)

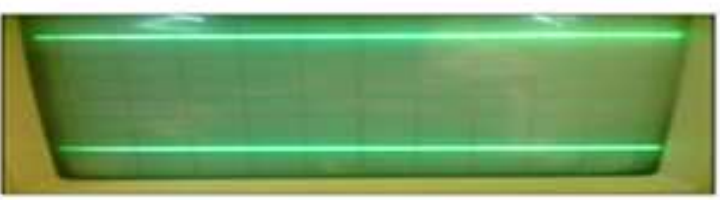

(2d)

Figure 2. Generation of regulated DC voltage signals

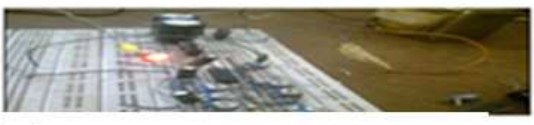

(3a)

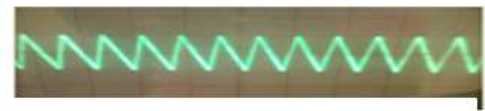

(3c)

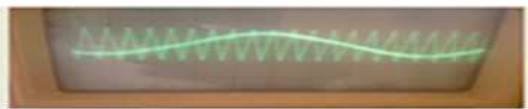

(3e)

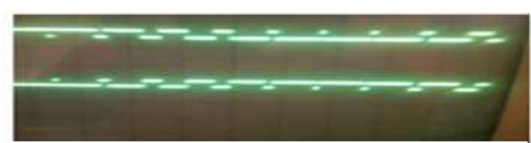

$(3 \mathrm{~g})$

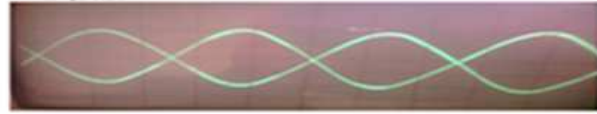

(3b)

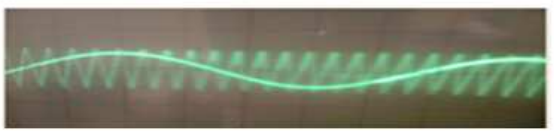

(3d)

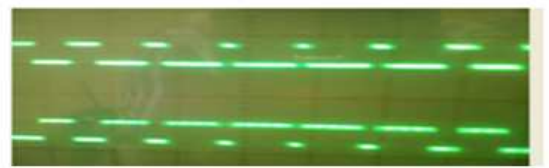

(3f)

Figure 3. Generation of triggering pulse-width modulated signals

The figure. $3 \mathrm{~b}$ indicates the sine signal waveform and its phase-shifted form by $180^{\circ}$. Figure $.3 \mathrm{c}$ shows the carrier waveform. The comparison of carrier wave and the two opposite sine waves are shown in figures $3 \mathrm{~d}$ and $3 \mathrm{e}$. The generated pulse-width modulated signals for triggering the inverter switches S1, S2, S3 and S4 are illustrated in figures $3 \mathrm{f}$ and $3 \mathrm{~g}$.

\section{Modulation Index}

Modulation index of a modulation scheme describes by how much the modulated variable of a carrier changes around its unmodulated level [1]. The modulation index of the above sinusoidal pulse-width modulation (SPWM) can be expressed as 


$$
m_{a}=\frac{V_{m}}{V_{c r}}
$$

Where $\mathrm{m}_{\mathrm{a}}$ - modulation index, $\mathrm{V}_{\mathrm{m}}$-amplitude level voltage of sine wave signal, $\mathrm{V}_{\mathrm{cr}}$ - amplitude level voltage of carrier wave signal.

From the figure $3 \mathrm{~d}$, the amplitude level voltage of sine wave signal is $4.80 \mathrm{~V}$ and the peak level voltage of carrier wave signal is $5.00 \mathrm{~V}$. When they are substituted appropriately in equation.9, the modulation index of the system becomes 0.96 . This obviously assists in mitigation of the switching losses of the power Mosfets (IRFp450) of the converter. In order to aviod shorting of the inverter legs, isolators are utilized.

\section{Isolation of the Inverter Switches Using IC (4N35)}

The isolation circuit ensures that there is no over voltage damages between the gating IC and MOSFETs. It equally solves the problem of "hanging earth" at the upper side inverter circuit. The output from the pin 2 of 4049 is passed into the pin 1 of the $4 \mathrm{~N} 35$ as illustrated in figure 6 . It is from this isolator that the MOSFET is then fed. The source terminals $\mathrm{S} 1$ and $\mathrm{S} 3$ are isolated because they are hanging while the terminal sources of S2 and S4 are not because they are already grounded.

\section{Single Phase Inverter Hardware Development}

The major hardware components of the inverter of the prototype are: MOSFETs (IRFp450), Clamping diodes or pin diodes, wooden board, Aluminum sheet

\subsection{Procedure}

Four equal aluminum metals of $6.00 \mathrm{~cm} \times 7.00 \mathrm{~cm}$ were measured and cut out from the sheet, and three holes were drilled diagonally on each surface; where the screws would be passed to hold them. A wooden board of $43.50 \mathrm{~cm} \mathrm{x}$ $81.00 \mathrm{~cm}$ was equally measured and placed. Then the aluminum metals were placed, and screwed with the Mosfets on the board's surface. Four holes were drilled on the wooden board where the pin diodes were passed through for proper connections. The bread boards were placed and the ICs were inserted on them. In connection of the Mosfet power switches; at upper two switches, DRAIN-TO-DRAIN connection method was used whereas at lower switches, SOURCE-TO-SOURCE prevailed. To connect the upper and lower switches, it becomes SOURCE-TO-DRAIN. While the connections were going, the continuity tests were carried out to ensure proper connections [4]. After connections, the pin diodes and the MOSFETS were properly soldered. The prototype of the work is shown in figure 6

\section{The Operation of the Single-Phase PWM Full Bridge Inverter}

Once there is any interruption from the utility supply, such as power failure or blackout, the $12 \mathrm{~V}$ battery powers the inverter. The processed PWM signals from the inverter logic gate (HEX 4049) and AND logic gates (4071B) are sent to the gate terminals of $S_{1}$ and $S_{2}$ through the 4 N35 to turn them $\mathrm{ON}$ and switch OFF the gates of $\mathrm{S}_{3}$ and $\mathrm{S}_{4}$ off for about 10milliseconds.

These applied signals establish voltages between gate and source $\left(\mathrm{V}_{\mathrm{GS}}\right)$ which are greater than the threshold voltages of the gates to be able to open up the channel of the MOsfets, then the voltages across the drains and the sources pump the available electrons from the sources to the inversion layer which converts the direct current to half positive non-sinusoidal alternating current and voltage. On the other hand, during negative half cycles, $\mathrm{S}_{3}$ and $\mathrm{S}_{4}$ are turned ON for $10 \mathrm{~ms}$ and $\mathrm{S}_{1}$ and $\mathrm{S}_{2}$ are turn OFF after a delay of $0.2 \mathrm{~ms}$. The continual turning ON and OFF of switches $\left(\mathrm{S}_{1}\right.$ and $\mathrm{S}_{2}$; $\mathrm{S}_{3}$ and $\mathrm{S}_{4}$ ) produced a full cycle of square wave. This square wave A.C was passed through the $\mathrm{L}-\mathrm{C}$ filter which resulted in pure sine wave. The oscilloscope diagram of it dc-ac converter is shown in figure 4 .

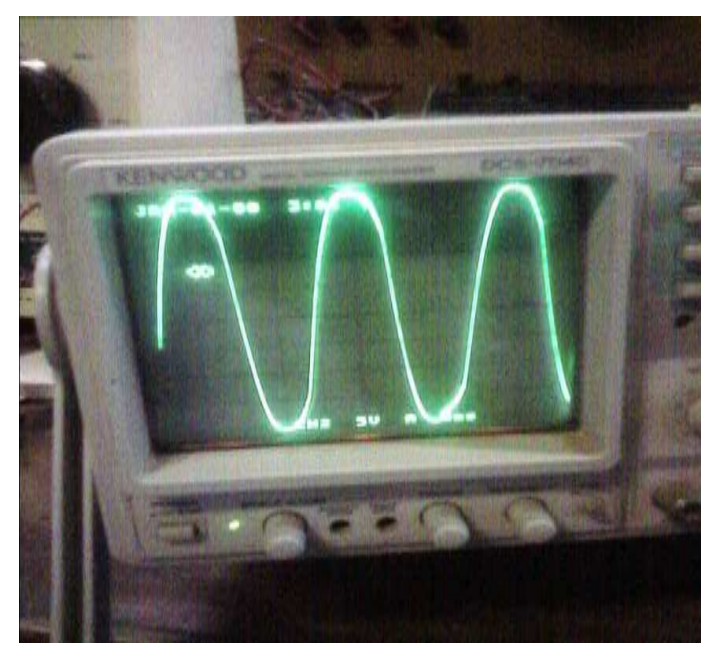

Figure 4. filtered inverter output current at THD of 5.05\%

The circuit of the ISBUPS consists of the battery of $12 \mathrm{~V}$, PI controller, the comparator, LM311, boost converter, inverter, filter (LC of $\mathrm{L}=\{0.5+0.5\} \mathrm{m}$-henrys and $\{20+20+20+20\}$ microfarads), resistor load of $100 \mathrm{k}-\mathrm{ohms}$ and summer. Circuit diagram of uninterruptible power supply with battery system is shown in figure.5.

The full bridge rectifier $\left(D_{1}, D_{2}, D_{3}\right.$ and $\left.D_{4}\right)$ rectifies the a.c voltage from the transformer to dc voltage. The capacitor charges up to the line voltage and releases the voltage to the inverter part. Through the action of turning ON and OFF of the switches, Ac voltage of $220 \mathrm{v}$ is produced at the inverter output terminals unfiltered. When the alternating current passes through the $\mathrm{L}-\mathrm{C}$ filter $(\mathrm{L}=1 \mathrm{mH}$, it produces a sinusoidal current and voltage signals. 


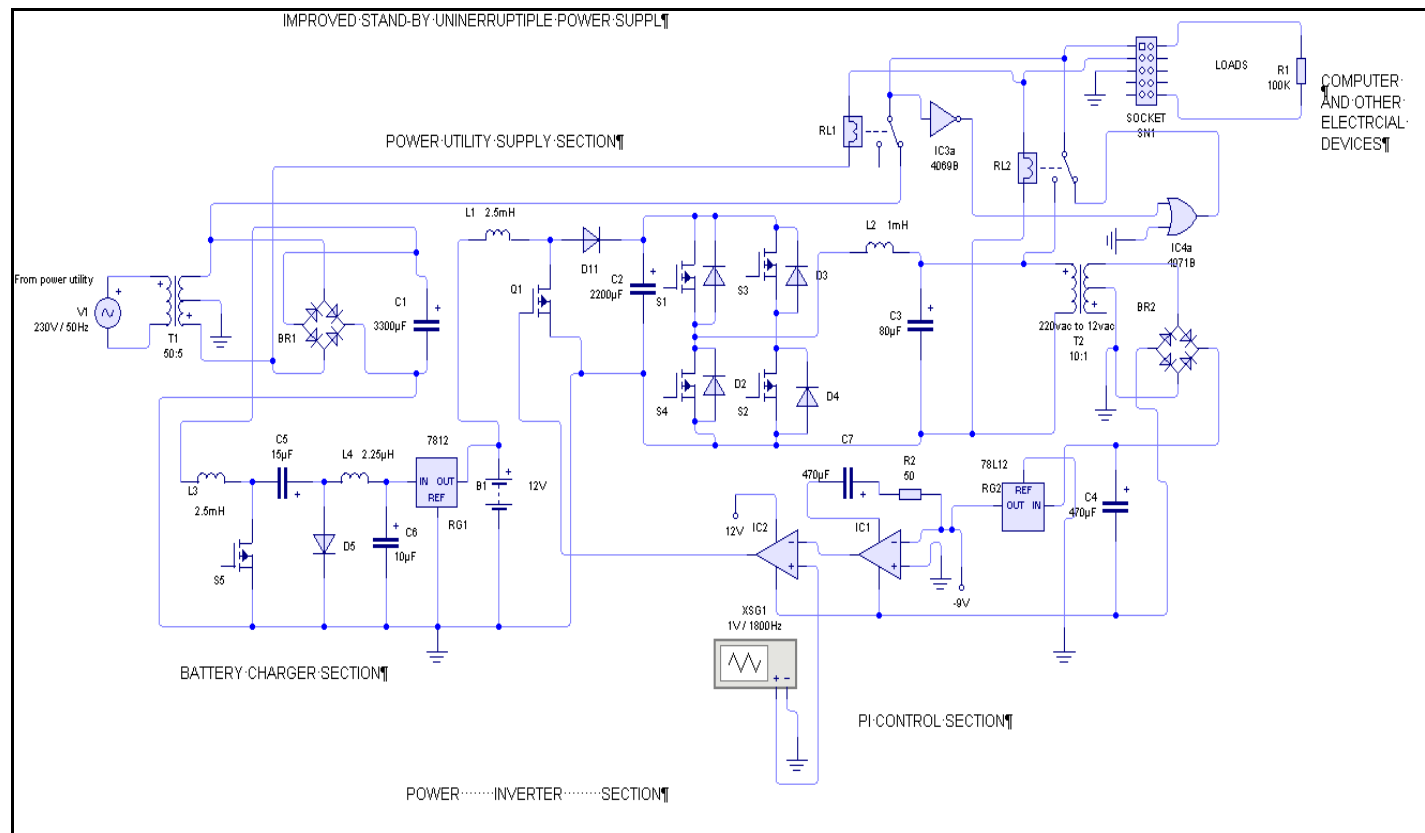

Figure 5. Basic circuit diagram of Improved Standby boost uninterruptiple power supply with battery backup system.

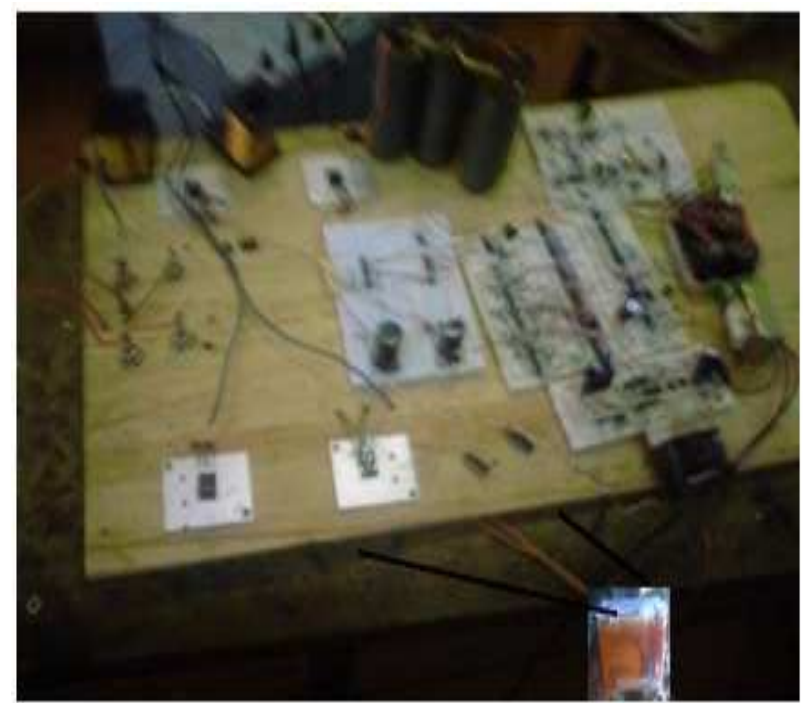

Figure 6. A prototype of ISBUPS with battery back-up System.

Another transformer (step down type) converts the 220v ac to $12 \mathrm{vac}$ followed by a full bridge rectifier $\left(\mathrm{D}_{5}, \mathrm{D}_{6}, \mathrm{D}_{7}\right.$ and $\mathrm{D}_{8}$ ) which changes the $12 \mathrm{vac}$ to $12 \mathrm{VDC}$. The capacitor bank ensures a ripple free DC voltages and currents. The 12VDC is sum up with a reference -9VDC at Op Amps connected after the capacitor. This then produces no error voltage. But if the voltage decreases, the summer will sum the two signals to produce error voltage and currents. The error dc voltage will be compared with triangular wave from figure 4 by the LM311. This produces pulse signals. The pulse signals generated are passed into the PI controller. The proportional term, determines the value of the error voltage or currents and then signals the driving circuit to turn $\mathrm{ON}$ the boost switch for voltage stabilization. When the boost switch starts operating, the $\mathrm{P}$ term determines the error voltage to be compensated in geometrical progression. If the speed at which the compensation of the lost voltage is not enough, the integral part (term) will adjust the band width of the pulses to quicken up the rate of stabilizing the voltage. The continuous process in case of either voltage decrease or increase will be regulated. The scope display voltage stabilization is shown in figure 7

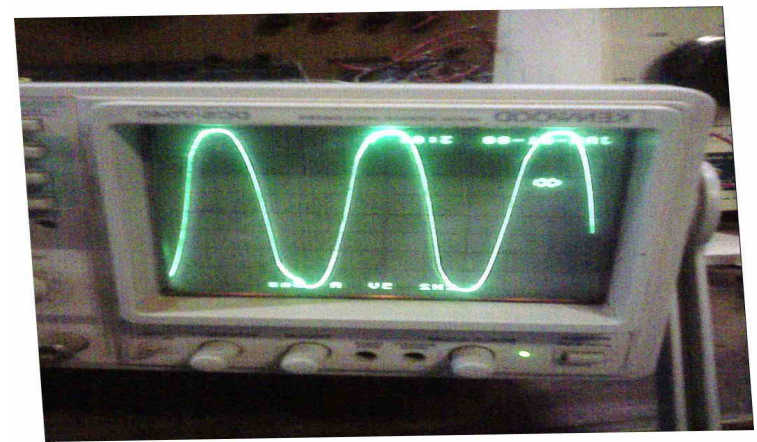

Figure 7. voltage stabilization of ISBUPS topology at 220V AC.

\section{Limitation of the Work}

The insulated gate bipolar transistor, IGBT switches would have been the best option for power switches in this work as a result of its high handling power capabilities than the metal oxide field effect transistors, MOSfets used. However the Mosfets were used because of its availability in our local market. Hence, this issue restricted the application of the IGBT switches. 


\section{Conclusion}

This paper practically elucidated the step-by-step method of realizing the proposed system with circuits and oscilloscopic signal displays. It also shows how the proposed system handles power supplied to the loads especially at the time of utility power interruptions. The modulation index of 0.96 and voltage stabilization at 220VAC got demonstrated the feasibility of reducing the power and switching losses maximally. Therefore, the mitigation of power and switching losses with the help of low-pass filter and sinusoidal pulse-width modulation scheme tremendously assisted in freeing the whole system from harmonics distortion (5.05\% as against $48 \%$ in [13]). Another advantage of this work is that its control system is very simple. Hence, for the future of this work, I wish to recommend microcontroller based systems to minimize the cost of many components and then, IGBT power switches should also be applied.

\section{References}

[1] Muhammad H.Rashid, "Power Electronics, Circuits, Devices and Application," Fourth Edition, Pretice-Hall of India, 2013.

[2] My Ton, Brian Fortenbery and William Tschudi, "DC power for Improved Data Center for Efficiency, " Lawrence Berkeley National Laboratory, March 2008.

[3] Mohan N and T. Undeland, "Standby Power Supply with Load-Current Harmonics Neutralizer, " United State Patent, Patent Number US 5334877A, August 2, 1994.

[4] Bong Hwan, Jin-Ha. And Tae-Won Kim, "Improved Single-phase Line-Interactive UPS, "IEEE Trans.Ind. Electron, Vol.48, pp.804-811, 2001.
[5] K. Hirachi, " Cost-effective practical developments of a high performance and multifunctional UPS with new system configurations and their specific control implementations, IEEE, PESC'95, 480-485, 1995.

[6] Giu-Jia Su and Tetuhiko Ohno, "A New Topology for Single Phase UPS Systems", IEEE 1997, pp. 913-918.

[7] Zhang, Y.H., Viathgamuwa, D.M., Choi, S.S., "An Experimental Investigation of Dynamics Voltage Restorer" Power Engineering Society Summer Meeting, 2000. IEEE, Vol.4, .2745-2750.

[8] Candidus.U.Eya, C.Odeh, D.B.N Nnadi, M.U, S.E Obe, "Utility Interfaced PWM of Solar fed Voltage Source Inverter Using Fixed-band Hysteresis Current Controller Method," Nigeria Journal of Technology, Vol.31, N0.1, March , 2012, pp.48-57.

[9] Raffia Akhter, Aminul Hoque, "Analysis of aPWM Boost Inverter for solar home application, ”, CISE 2006, International Conference, Enformatika, Volume17, December 2006.ISSN 1305-5313, pp.212-216.

[10] C. Cecati, A. Dell' Aquila and M. Liserre, "Analysis and control of a three-phase dc/ac step-up converter", in proc. IEEE ISIE'02 Conf., pp. 850-856, July, 2002

[11] M.I.M. Monteiro , E.R. Cadaval, and F.B Gonzalez, "Comparison of Control Strategies for Shunt Active Power Filters in Three -Phase Four-Wire System, " IEEE Trans. On Power Electronics, vol.22, no. 1, pp 229-236, Jan, 2007

[12] P. Salmaron, S.P Litra, S.R Herrera, , and J.R Vazquez, "Practical Comparative Evaluation of Different Active Harmonic Filter Topologies, " in Proc. of f ICREPQ, 2011

[13] R.A Modesto, S.A.O.Silva, R.Barriviera and M. Kasster, "Analysis of a Single-Phase Line-Interactive UPS System," Santago de Compostela (Spain), 28th to 30th March, 2012. 